\section{SCHWERE INFLUENZA}

\section{Rauchen im Haushalt verdoppelt die Gefahr für Kleinkinder}

- Das Risiko für einen schweren Verlauf von Influenza ist für kleine Kinder besonders groß. Es verdoppelt sich noch, wenn das Kind in einem Haushalt mit Rauchern oder geringem Einkommen lebt, die Mutter sehr jung ist oder der Impfkalender nicht eingehalten wurde. Der stärkste Risikofaktor für eine Klinikaufnahme als Marker einer schweren Grippe scheint dabei das häusliche Rauchen zu sein. Ergeben hat dies eine Fall-Kontroll-Studie aus den USA, die aktuell bei der Jahrestagung der Infectious Diseases Society of America (IDSA) in Vancouver, Kanada, vorgestellt wurde. In der retrospektiven Analyse mit den Daten einer Impfstudie wurden insgesamt mehr als 1300

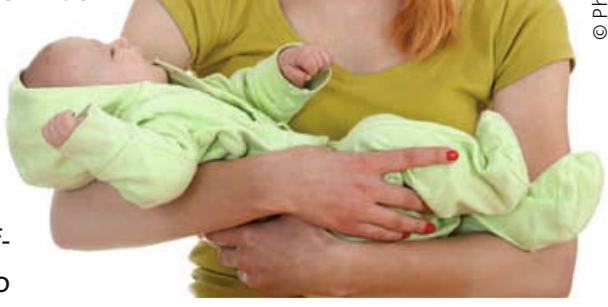
Kinder (im Alter zwischen 6 und 59 Monaten) mit bestätigter Influenzaerkrankung betrachtet. 290 Kinder mussten innerhalb von 14 Tagen nach Erkrankungsbeginn ins Krankenhaus. Wenn mehr als die Hälfte der Familienmitglieder im Haushalt eines Kindes rauchten, lag die Odds Ratio für eine Klinikaufnahme des grippekranken Kindes bei 2,3, das Risiko war also mehr als verdoppelt. War die Mutter jünger als 22 Jahre, lag sie bei 2,1, ebenso bei einem Haushaltseinkommen unter der Armutsgrenze. Waren die altersentsprechend empfohlenen Impfungen nicht vollständig, lag die Odds Ratio immerhin noch bei 1,7.

SPA =

Oral Abstract Session; Influenza: Epidemiology, Clinical Features, and Prevention In Children and Adults Saturday, October 23, 2010: 2:45 PM

Dharan NJ et al. Child and Household Risk Factors for Hospitalization with Laboratory-Confirmed Influenza Among Children Aged 6-59 Months - United States 2005-2008. IDSA 2010, Abstract 1430

\section{SYMPATHIKUS HYPERAKTIV, VAGUS TRÄGE}

\section{Wie Stress die Haut stresst}

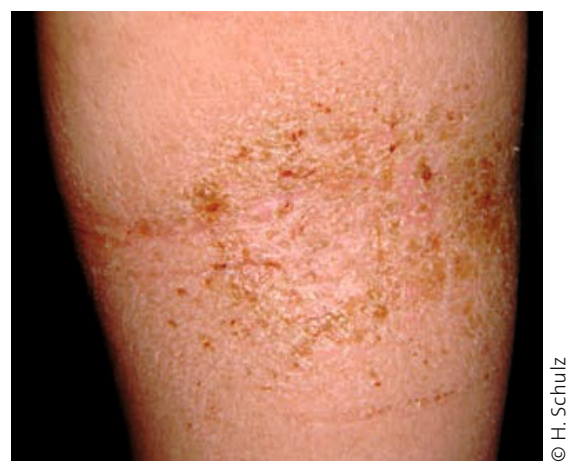

Auf Stress reagiert Neurodermitikerhaut besonders empfindlich.

\section{ADIPOSITAS}

\section{Fischöl zur Diabetesprophylaxe?}

- Antientzündliche Effekte von Omega3-Fettsäuren werden über einen speziellen Rezeptor auf Makrophagen im viszeralen Fettgewebe vermittelt. Über ihn könnte eine entsprechende Diät chronische Entzündungsprozesse und Insulinresistenz bei Adipösen vermindern.

Forscher um Jerrold Olefsky von der Universität Kalifornien in San Diego fokussierten bei ihrer Arbeit auf den G-ProteinCoupled-Rezeptor (GPR) 120, weil er spezifisch auf proinflammatorischen Makrophagen im Fettgewebe zu finden ist. Ist er inaktiv, produzieren die Makrophagen vermehrt Entzündungsmediatoren wie Zytokine. Die Omega-3-Fettsäuren DHA und EPA aktivieren ihn. Die Forscher fütterten adipösen Mäusen mit und ohne GPR 120 eine Hochfettdiät mit Omega-3Fettsäuren-Zusatz. Bei den Mäusen mit GPR 120 waren eine geringere Entzündungsaktivität und eine bessere systemische Insulinsensitivität mit der Supplementation feststellbar, bei den GPR-12OKnockout-Mäusen dagegen nicht.

Die Wissenschaftler schließen aus ihren Ergebnissen, dass GPR 120 ein potenter Vermittler antidiabetischer Effekte ist. Er könnte auch ein Ansatzpunkt für neue Medikamente sein, die den Fettsäureeffekt simulieren.

SPA =

Oh da Y et al. GPR120 is an omega-3 fatty acid receptor mediating potent anti-inflammatory and insulin-sensitizing effects. Cell. 2010;142(5):687-98.

Provokation des Juckreizes erfolgte mittels Histamin-lontophorese. Die zwei weiteren Stressoren bestanden in standardisiertem Kratzen des juckenden Areals und in einem psychologischen Stresstest.

Die Ergebnisse zeigten deutliche Unterschiede zwischen den beiden Gruppen:

- AD-Patienten hatten generell eine höhere Herzfrequenz, und ihre sympathische Antwort auf Juckreiz und Kratzen fiel kräftiger aus.

- Die vagale Reaktion auf die Stressoren bei den AD-Patienten war gestört. 